\title{
A L'ENTORN DELS CURSOS DE FORMACIÓ BÀSICA PER A LA REFORMA DE L'ETAPA PRIMÀRIA
}

\section{Es pretén donar una formació bàsica}

Els cursos de formació bàsica per a la Reforma, dirigits als mestres de Cicle Inicial de l'escola pública i privada concertada, van començar el gener $i$ acabaran el juliol d'aquest any. Els objectius que hom pretén aconseguir són amplis. El Departament d'Ensenyament els concreta en quatre:

- Donar a conèixer la nova orientació del sistema educatiu i les innovacions més significatives de caire psicopedagògic i estructural que introdueix.

- Afavorir el coneixement del Disseny Curricular de l'Etapa de Primària com a instrument de renovació pedagògica, de reflexió sobre els diferents continguts de l'ensenyament $i$ de sistematització de la tasca docent.

- Donar elements per poder desenvolupar el currículum en el cicle, d'acord amb el Projecte Educatiu del Centre.

- Capacitar el professorat per contrastar la seva pràctica educativa en el Cicle Inicial amb els plantejaments psicopedagògics i didàctics de la Reforma.

El contingut del curs s'ha caracteritzat per una quantitat important d'informació teòrica, per poder partir d'una reflexió aprofundida a l'entorn de la necessitat d'una renovació pedagògica que condueixi a una major qualitat de l'ensenyament.

S'ha vist la necessitat que els mestres tinguin una informació bàsica en els aspectes següents:

- El desplegament de la LOGSE.

- Aspectes psicopedagògics fonamentals dels quals caldrà partir perquè els nens puguin construir, de manera comprensiva, els aprenentatges.

- Considerar a partir d'ara com a "contingut" tant el que fa referència als aspectes conceptuals com procedimentals i actitudinals.

- Coneixement dels tres nivells de concreció on es defineixen les competències de les diferents institucions educatives, des dels mínims que estableix l'administració, passant per una organització curricular d'escola, fins a la programació de cicle i d'aula a través d'uns instruments que possibilitin l'elaboració d'un projecte d'escola (Projecte Curricular de Centre) adaptat a les peculiaritats de cada centre.

- Informació curricular de les àrees de llengua i matemàtica.

\section{Les aportacions dels mestres que assisteixen als cursos}

A les nostres comarques s'han inscrit més del 90 $\%$ dels mestres convocats. Aquesta assistència majoritària demostra l'interès que d'entrada desperta la Reforma a l'Ensenyament Primari i, més en concret, al Cicle Inicial.

Al llarg del desenvolupament dels cursos, i d'una manera també majoritària, el professorat ha manifestat una especial preocupació perquè es pugui aplicar la Reforma al'Ensenyament Obligatori en els tres aspectes següents:

- El treball en equip.

- L'atenció a la diversitat.

- La Reforma a Secundària.

\section{El treball en equip}

Es veu d'entrada la necessitat que hi hagi un treball coordinat entre els membres del claustre d'una escola. La realitat escolar actual, en la majoria dels casos, comporta una sèrie de handicaps que dificulten la coordinació pedagògica entre els diferents cicles educatius. En canvi, es valora com a força acceptable el treball en equip per cicles.

L'opinió del professorat assistent als cursos és que s'amplia considerablement el paper del cap d'estudis, sobre el qual cau la responsabilitat de coordinar l'elaboració del Projecte Curricular de Centre, a la vegada que expressen que l'equip directiu ha de ser el dinamitzador del treball del claustre, de tal manera que cada mestre en particular $i$ tots en general portin a la pràctica els acords presos.

Un dubte, també molt compartit, és el fet que l'administració no deixa prou clar quina serà la disponibilitat horària per poder realitzar setmanalment aquest treball dins l'horari laboral del mestre. Creuen que aclarir aquest punt és bàsic i previ a tots els altres aspectes pedagògics $\mathrm{i}$ organitzatius de l'esmentat treball en equip. 


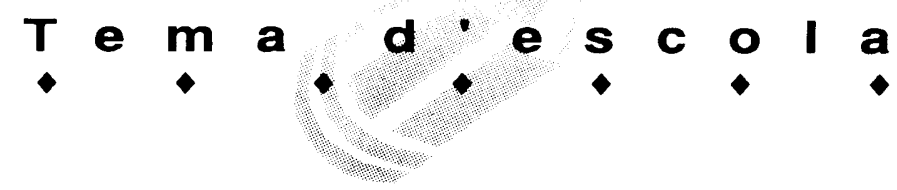

\section{Atenció a la diversitat}

Aquest aspecte, d'uns anys ençà, és molt important. Els mestres palesen que l'alumnat és cada vegada més divers (immigrants de països àrabs, orientals, nens d'integració amb deficiències psiquiques ifísiques, nens de families marginades i / o de famílies desestructurades, etc.) i que, per tant, els esforços que per atendre'ls s'han de fer augmenten d'any en any.

Constatem que es necessiten unes condicions que no sempre es donen; infrastructura adient (per exemple, rampes), matrícula baixa, recursos humans suficients (EAPs, especialistes d'Educació especial, mestres amb disponibilitats horàries dins de l'horari lectiu per a reforçar dins de l'aula el treball del tutor, etc), recursos materials que poden consistir en propostes de treball ja elaborades, orientacions per elaborar nous materials, equipaments per atendre deficiències específiques, etc. Hom reclama una formació més aprofundida de tots els professors en aquest tema.

\section{La Reforma a Secundària}

D'aquest punt els professors de Primària tenen diverses preguntes referides al professorat que impartirà l'Ensenyament Secundari Obligatori. Quina és la seva actitud davant la Reforma? L'obligatorietat d'aquesta estapa suposa molts canvis, entre ells l'atenció a la diversitat. Tindran suficients recursos per atendrela? Tenen la voluntat $i$ els mitjans necessaris per preparar-se, per rebre els alumnes a partir dels 12 anys? Veuen la necessitat de coordinar-se amb els centres de Primària, d'on procedeixen els seus alumnes, amb l'objectiu que hi hagi una veritable continuïtat en tot l'ensenyament obligatori? Estan o estaran ben informats sobre quins són els objectius bàsics de l'Ensenyament Primari?

Per últim, els mestres creuen que el desenvolupament positiu o negatiu de la Reforma a Secundària Obligatòria repercutirà directament i immediata a Primària, i voldrien tenir la certesa que la repercussió serà positiva.

\section{Altres aspectes}

- S'espera amb impaciència la reestructuració dels claustres, a causa del pas dels alumnes de l'actual 7è i 8è d'EGB a l'Ensenyament Secundari Obligatori.

- S'està a l'expectativa de quina serà la quantitat de recursos materials i sobretot humans que tindrà cada centre...
- Es comenta la influència (positiva, negativa?) dels llibres de text en l'elaboració dels projectes curriculars de centre i de les Unitats de Programació.

- Hi ha la demanda de formació en el propi centre sobre els aspectes següents:

- L'aprofundiment de les àrees.

- L'elaboració del projecte curricular d'escola.

- La confecció d'unitats de programació.

- Es veu la necessitat d'informar els pares sobre les innovacions organitzatives $i$ pedagògiques que aporta la Reforma: nova ordenació del sistema educatiu, ús dels llibres de text, com s'entén l'avaluació, utilització selectiva de la claculadora, priorització dels aprenentatges procedimentals sobre els conceptuals, etc.

- Es valora com a molt positiu que el Departament editi un exemple de segon nivell de concreció i exemples d'unitats de programació.

Els mestres formadors hem viscut molt directament l'interès de la majoria de mestres de Cicle Inicial a rebre una formació bàsica sobre la Reforma. De totes les intervencions que hi ha hagut per part dels assistents, la majoria d'elles han estat positives en relació a les bases psicopedagògiques que presenta la Reforma. S'està d'acord a orientar l'aprenentatge dels alumnes cap a una formació que repercuteixi en el desenvolupament global del nen. Els mestres, davant una sèrie de reflexions psicopedagògiques, no es neguen en absolut a actuar en coherència amb aquestes bases; la preocupació ve en el moment en què es planteja la manera de portar a terme tota la nova proposta. Quan arribem en aquest punt, convé aclarir que cal començar amb una planificació abastable als recursos que es tinguin i amb una temporització de dos, tres, quatre... anys, i els que calguin, perquè resulti una tasca productiva, agradable i de possible aplicació. Malgrat tot, hi ha un cert estat d'angoixa, tenint en compte que hi ha un calendari d'aplicació $i$ que ha de ser la pròpia escola, de moment, qui ha de decidir les prioritats que s'hauran de tenir en compte per començar, i que, segons els recursos de què es disposi, es pugui eternitzar la seva posada en marxa i perdre el fil d'allò que s'havia planificat prèviament.

També es constata la necessitat que els equips directius i els mestres de Cicle Mitjà i Superior (a més dels de Parvulari) facin aquest curs de formació bàsi$c a$, perquè amb una base comuna sigui més fàcil començar a fer camí a cada centre. 


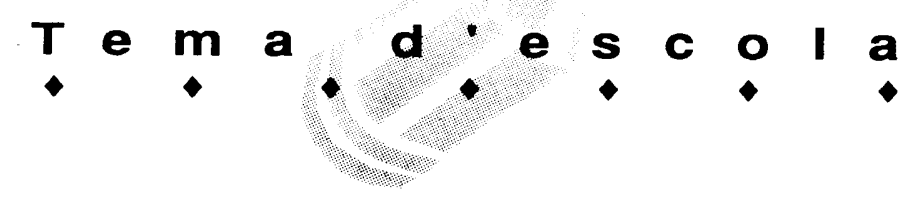

\section{Suggeriments per a una immediata aplicació}

S'ha fet el primer pas cap a l'aplicació de la Reforma amb la formació del professorat. Els mestres de Cicle Inicial són els primers que han entrat per la porta de l'escola amb una formació bàsica que possibilita tenir un coneixement general per poder començar a pensar en la seva aplicació. De moment serà difícil determinar les actuacions que s'han de posar en marxa perquè l'escola faci la seva planificació, ja que els membres de molts equips directius, principalment els caps d'estudis, no han estat formats. L'administració té prevista aquesta formació, sembla ser, en un termini molt curt.

Ja hi ha alguna escola que, malgrat tot, ha iniciat un debat intern per començar a perfilar els primers passos que condueixen cap a una planificació. Una possibilitat podria consistir a dissenyar un pla de quatre anys a desenvolupar a través dels plans anuals de centre. Aquesta idea podria donar una visió més global, a la vegada que delimitaria la tasca de cada curs. Durant aquests quatre anys es podria establir un pla de treball anual definint de manera clara les actuacions que s'haurien de fer en els tres nivells següents:
- Claustre

- Cicles

- Professors

\section{Claustre}

- Confecció o revisió del Projecte Educatiu de Centre (PEC) adaptat a les actuals circumstàncies. Intern.

- Confecció o revisió del Reglament de Règim

- Elaboració del Projecte Curricular de Centre (PCC), el qual contempla els apartats següents:

1. Objectius generals del centre i de les etapes.

2. Objectius generals $i$ continguts de les àrees.

3. Objectius generals de l'àrea per cicle.

4. Seqüenciació dels continguts per cicles.

5. Opcions metodològiques.

6. Materials curriculars i recursos didàctics.

7. Criteris d'avaluació.

8. Criteris de promoció de cicles.

- Decisió en la priorització de l'ordre sobre com s'han d'anar desenvolupant cadascun dels components del PCC. Es recomana que es comencin a redactar aspectes que ja es tenen clars perquè s'han acordat en cursos anteriors.

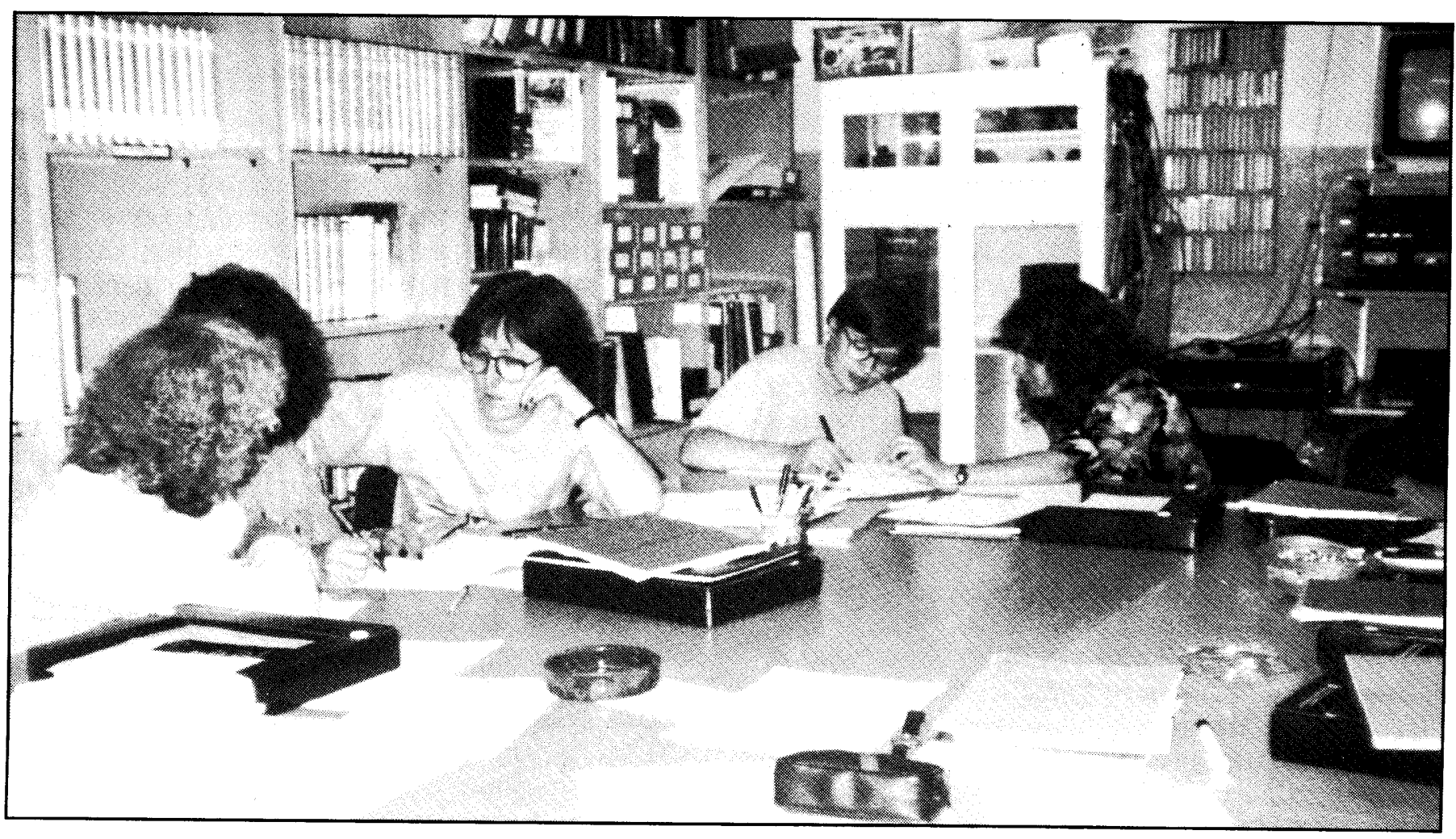




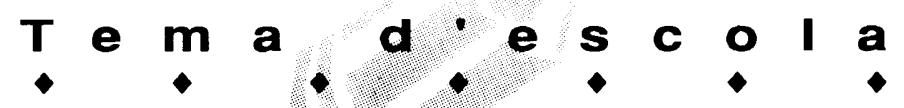

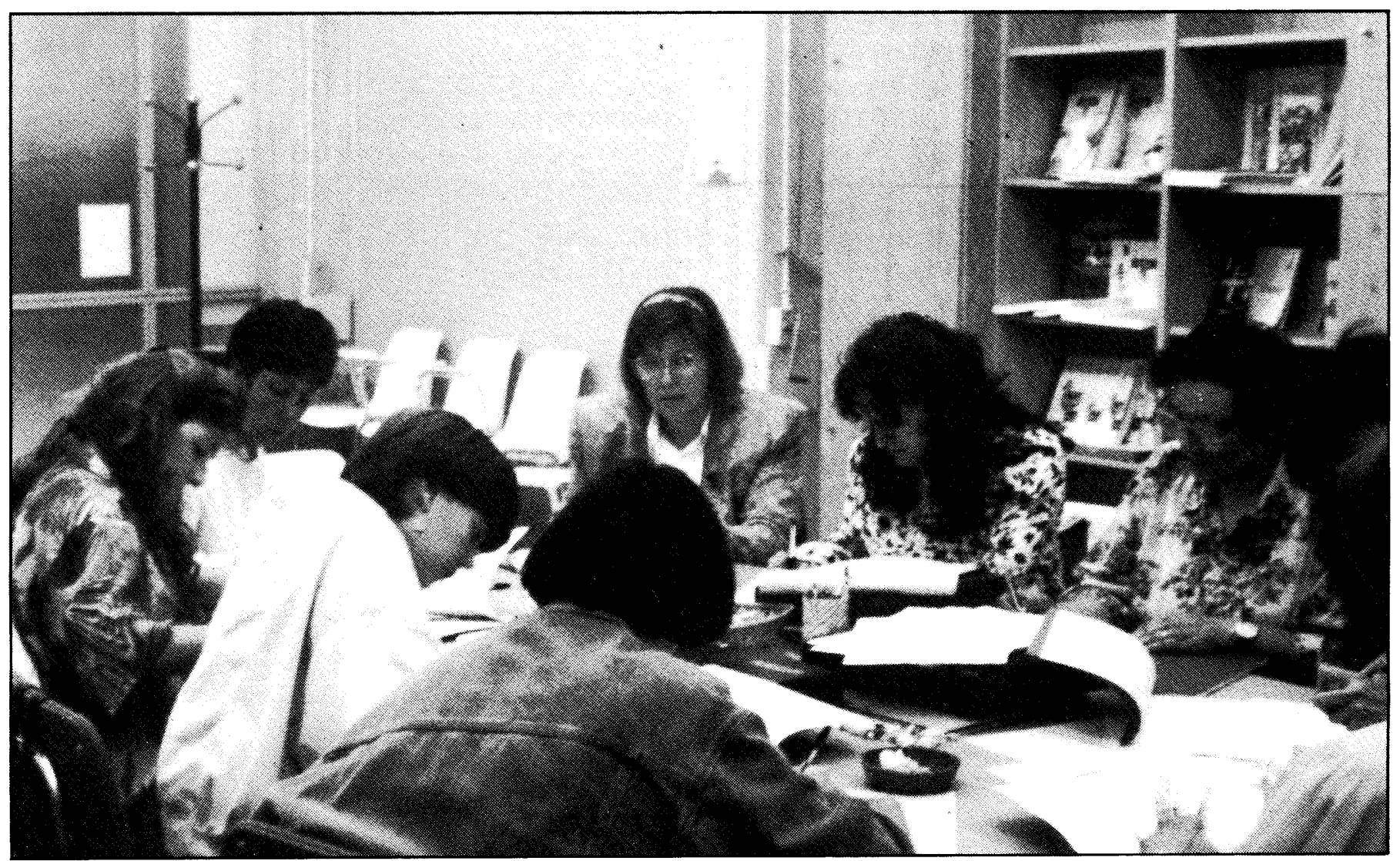

- És possible que el redactat dels 3 primers punts siguin relativament fàcils d'acordar, tenint en compte que es tracta de contextualitzar els objectius generals de les etapes i de cadascuna de les árees del primer nivell de concreció.

- Quant als últims 5 punts, serà necessari sistematitzar i delimitar a través dels plans anuals dels 4 anys consecutius el que es preveu de tractar a cada curs.

- EIPCC ha de respectar els principis pedagògics, organitzatius, ideològics, etc. del PEC.

\section{Cicles}

El proper curs inicien l'aplicació de la Reforma el segon cicle de l'etapa infantil (parvulari: 3,4 i 5 anys) i el cicle inicial de l'etapa primària.

Els mestres de Parvulari i Cicle Inicial han de decidir de quina manera començaran a aplicar la Reforma. El més recomanable seria partir del pla establert per tota l'escola en el període de 4 anys per assegurar amb coherència la línia pedagògica del centre. Tant l'equip de Parvulari com el de Cicle
Inicial, a partir del curs $1992-93$ podrien començar a concretar els aspectes següents:

- Planificar la programació de cicle:

- Elaboració del $2 n$. nivell de concreció de Cicle Inicial.

- Planificació en Unitats de Programació de totes les àrees d'aprenentatge.

- Decisions metodològiques (globalització, tractament disciplinar de les àrees, racons...) que vagin d'acord amb el PCC. Abans d'elaborar unitats de programació, convindria establir la metodologia que estigui d'acord amb les bases psicopedagògiques de la Reforma.

- Començar a adaptar aspectes de programació que seran prescriptius en l'aplicació de la Reforma; per exemple: en matemàtiques, la priorització del càlcul mental al càlcul escrit; en llengua, la tipologia de textos, etc.

- Escollir els materials curriculars (llibres de text, quaderns, materials complementaris...). Cal no perdre mai de vista que les decisions que puguin afectar la 


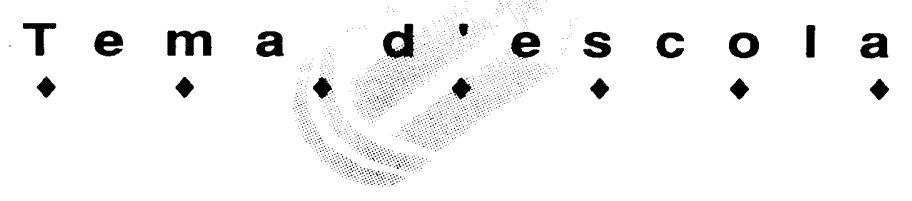

resta dels cicles s'han de consensuar a través de la intervenció del cap d'estudis i / o dels acords del claustre.

- Criteris d'avaluació: Partir d'uns acords bàsics de l'equip de mestres (claustre) o bé del PCC. Els criteris d'avaluació han de tenir en compte les orientacions del primer nivell de concreció, els objectius dels aprenentatges i la informació que caldrà donar als pares (informes), al cicle $i$ al claustre.

- Començar a elaborar unitats de programació d'acord amb les opcions metodològiques i els materials curriculars que s'utilitzaran.

El fet que el calendari d'aplicació sigui a partir del proper curs no hauria de repercutir a precipitar les actuacions dels mestres i a pretendre assolir objectius inabastables. Cal fer un treball inicial de reflexió perquè cada equip d'escola pugui compartir de manera consensuada els aspectes bàsics de la Reforma. Sabem que això suposarà un bon esforç per a molts mestres, sobretot per a aquells que hauran de modificar els seus esquemes de treball de molts anys, amb el conseqüent canvi d'actitud i en alguns aspectes amb unes prioritats fins ara no explicitades legalment. Queda clar, doncs, que no hem de pretendre veure resultats palpables en un curs; es tracta d'experimentar una progressiva evolució positiva, anar superant etapes i que en surti beneficiat l'alumnat, evitant qualsevol perjudici al professorat. Per dir-ho en forma d'eslògan: Hem de pensar que treballem per a l'escola de l'any 2.000 .

\section{Professors}

Tal com ja hem dit, el professor haurà d'assumir el seu paper responsabilitzant-se dels acords presos i actuar en coherència amb les decisions del claustre, cicle, etc.

De cara al proper curs, una possibilitat consistiria en l'elaboració d'una unitat de programació senzilla i en la seva aplicació a la classe. Podria estar relacionada amb un aspecte d'aprenentatge que el mestre tingués facilitat per desenvolupar i, si pot ser, fer-la conjuntament amb la resta dels mestres de cicle; d'aquesta manera li permetria superar amb més facilitat els obstacles que puguin sorgir.

Per posar en marxa tota la innovació curricular i organitzativa dels centres, confiem que l'escola no restarà sola, sinó que comptarà amb el suport de la inspecció i les ajudes que siguin necessàries a través dels Plans d'Activitats de Formació Permanent de Zona.

Josep Garriga Sancho Montserrat Ral Barberà Maria A. Sánchez Bellés Jordi Vallès Gené

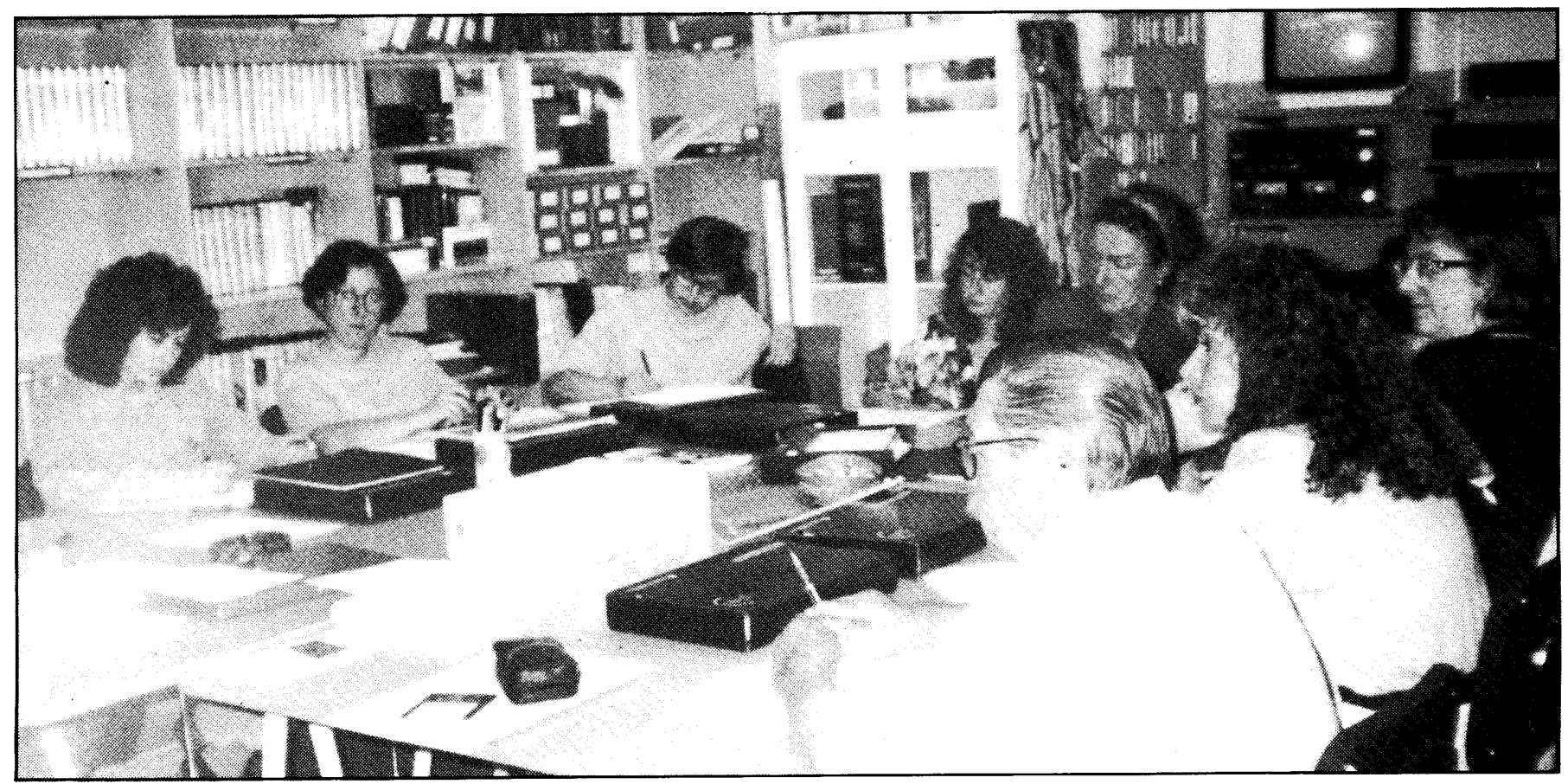

